\title{
Link Analysis and Web Influence Evaluation for Enterprise Websites
}

\author{
Junping Qiul, Quan'e Ren2 \\ 1 College of Information Management, Reseach Center for Chinese \\ Science Evaluation, in Wuhan Uninersity \\ jpqiu @whu.edu.cn \\ 2 College of Information Management, Reseach Center for Chinese \\ Science Evaluation, in Wuhan Uninersity \\ renquane @yahoo.com.cn
}

\begin{abstract}
As the enterprise Informatization process goes through deep, an increasing number of enterprises deploy their web sites on the internet, making the web sites become a brand of the enterprise. Thus, it is very necessary to evaluate the quality for enterprise web sites. However, almost the total current website evaluation methods have ignored the external web influence factors of quantitative evaluation and can't work effectively. In this paper, we employ the weblink analysis method to evaluate the web influence for enterprise web sites, combing 17 link analysis indicators obtained by Google and AltaVista. We then explored the relationship between the web sites type and web influence and discussed the performance of the link indicators and link analysis tools. The whole analysis is based on our experiments, using the data accepted from 2006 Top 500 companies list of China and 2006 Fortune 500 companies list in the world.
\end{abstract}

\section{Introduction}

Many indicators and methods have been proposed to evaluate the enterprise web sites in China and foreign countries, however, their focus are different. Few of them referred to the evaluation system of web sites link analysis and web influence $[6,13]$. At present, there are four typical evaluation system concerning on the electronic business web sites, such as: 5 indicators designed by Gomez, 10 indicators designed by BizRate, indicators used by the organization of CU' consumer reports online, CNNIN evaluation indicators[4], and indicators used by China Enterprise Confederation, information exchange center which belongs to China Entrepreneurs Association has launched an appraisal campaign on the web in 2005, only using standard as "Navigation clear, unmistakable link, homepage with links to columns point inflation rate of not less than $90 \%$. " to evaluate Internal Links[2].

Please use the following format when citing this chapter:

Qiu, J., Ren, Q., 2007, in IFIP International Federation for Information Processing, Volume 251, Integration and Innovation Orient to E-Socicty Volume1, Wang, W. (Eds), (Boston: Springer), pp. 300-308. 
From this, we divide the electronic business web sites evaluation methods into three parts: qualitative evaluation, quantitative evaluation and synthetically evaluation. The main methods of quantitative evaluation are the web traffics' indicators, often using, Alexa traffic. However, the rank is not absolutely authorities [1].

There is another quantitative evaluation method: using link analysis methods and web influence factor (WIF). Link analysis uses the webpage number of link which links to certain sites and represent its quality, this is based on these theories: if site $A$ is linked by site $B$, then that means B is appreciating and using $A$, and the content of $A$ and $B$ is relevant; the more the site is linked, the bigger is the web influence. WIF measurement is based on link analysis, using WIF to represent the web influence. Therefore, we attempt to apply link analysis method and WIF measure methods to evaluate some of the typical enterprise in China and foreign countries. What's more, we explore the relationship between the type of sites and web influence.

\section{Research approach}

\subsection{Research swatch}

Because the difference exists in industry and which will influent the effect of link analysis, we define the swatch in information technology enterprises and consumable electron enterprises. The American Forrest Research company has designed a Site Need Index (SNI) to help the enterprise to decide whether they need to build a site for popular products. SNI' research results show that information technology enterprises and consumable electron enterprises hurriedly need to build their own brands and products through web sites [3, 7]. In our experiment, we selected thirty-four enterprise sites form 2006 Top 500 companies list of China and 2006 Fortune 500 companies list in the world to be our research swath. And our focus is enterprises sites in China, several foreign enterprises are used to compare with domestic web sites.

\subsection{Indicators}

In order to represent the scale and web influence of the enterprise sites comprehensively, we choose seven link analysis indicators as follows :( the website evaluated is labeled with $A$ in this paper)

Pages Number: It represents the number of pages which are retrievable in search engines for A. It represents the scale of a website to some extent, but not necessarily represents the quality and concentration of a website.

Total Links: It is the number of pages indexed by search engines which are linking to A. This stands for the web influence of $\mathrm{A}$.

Internal Links: This is the number of pages in A indexed by search engines which are linking to A itself, that is to say, it is a kind of self-link. Self-link represents the hierarchy and fullness of A's inner structure. 
External links: It is the number of pages except $A$ indexed by search engines which are linking to website A. This is the primary indicator, which is even better than total links for representing web influence.

Web Influence Factor (WIF=Total Links/Total pages) reflects the average level of pages for A that are linked. It also is the calculation way for WIF proposed by Ingwersen [5].

External Web Influence Factor (WIFe=External Links/Pages Number) reflects the total average level of Internal links of $A$. It is an objective indicator.

Internal Web Influence Factor (WIFs=Internal links/Pages Number) reflects the total average level of Internal links of $A$

\section{Data Sources}

\subsection{Retrieval Methods and Tools}

In the webometrics, there are two kind of link analysis tools. One is commercial search engines, the other is professional crawler. Because an proper tools for measuring WIF should Satisfy five conditions [10], there yet aren't any commercial search engines fits for them all.

AltaVista is often used in the research on webometrics. In fact, both Google and AltaVista are good tools to finish this task, what's more, the coverage and capacity of data in Google is better than AltaVista[12]. Thus, both Google and AltaVista are used in our experiment to eliminate and balance the uncertainty of link analysis, and improve the reliability and efficiency of the research results. In this paper, different indicators and retrieval expressions are used in different tools, as showed in table 1 and table 2

Table 1: Indicators and Query Expressions used in Google search engine, taking Haier Group for example

\begin{tabular}{|c|c|}
\hline Indicators & Query Expressions \\
\hline Pages Number: $\mathrm{T}$ & site: www. haier. com \\
\hline Total Links: L & "WWw. WWw. haier. com" \\
\hline Internal Links: $S$ & "WWw. WWr. haier. com" site: WWw. haier. com \\
\hline External Links: E & "www hai er. com" -site: www. haier. com \\
\hline Web Influence Factor: WIF & $\mathrm{L} / \mathrm{T}$ \\
\hline External WIF: WIFe & $\mathrm{E} / \mathrm{T}$ \\
\hline Internal WIF: WIFs & $\mathrm{S} / \mathrm{T}$ \\
\hline
\end{tabular}

Table 2: Indicators and Query Expressions used in AltaVista search engine, taking Haier Group for example

\begin{tabular}{|c|c|}
\hline Indicators & Query Expressions \\
\hline Pages Number: $T$ & Host: www. haier. cont \\
\hline Total Links: $\mathrm{L}$ & Link: www. hai er. con \\
\hline Internal Links: $\mathrm{S}$ & $\begin{array}{l}\text { S1:link:www. haier. com AND host: www. haier. com } \\
\text { S2:host:www. haier. con AND link: wWw. haier.com }\end{array}$ \\
\hline External Links: E & $\begin{array}{l}\text { E1:1ink: WWw. haier. coll AND NOT ww. haier. com } \\
\text { E2:1ink: WWw. haier. com AND NOT wWw. haier. com link: }\end{array}$ \\
\hline
\end{tabular}




\begin{tabular}{|c|c|}
\hline & $\begin{array}{c}\text { www. haier. com }) \\
\text { E3:1ink: www. haier. com AND NOT www. haier. com host: } \\
\text { www. haier. com })\end{array}$ \\
\hline Web Influence Factor: WIF & L/T \\
\hline External WIF: WIFe & $(\mathrm{E} 1+\mathrm{E} 2+\mathrm{E} 3) / 3 / \mathrm{T}$ \\
\hline Internal WIF: WIFs & $(\mathrm{S} 1+\mathrm{S} 2) / 2 / \mathrm{T}$ \\
\hline
\end{tabular}

The accuracy 34 Sino-foreign enterprises' name and their website URL in our swatch are showed in table 3 . The experiment was done from May 1 to May 3,2007, using a quick accessing way to eliminate and reduce errors caused by dynamic net information.

Table 3: Name and URL of the companies

\begin{tabular}{|c|c|}
\hline Enterpriso Name & Enterpril=0 WOBNILO URL \\
\hline Microsofi Corporation & mow.microsoricicom \\
\hline IBM Company. & wrw. $1 \mathrm{bm}$.com \\
\hline DELL COmpany & wow. dell. com \\
\hline Intel Company. & wrw. Intel. com \\
\hline Oracto company & www. oracto, com \\
\hline IBM China Company Limilod & www. 1bm. com, en \\
\hline Founder Eloctronles Co, Ltd & wrw. founder, com \\
\hline Halor Co.. Led & wow. halox. com \\
\hline Nokla Maloland China & wrw. nokla, com, en \\
\hline zTE Corporation & www.xte.com. en \\
\hline Motorola china. & www, motorola. com, on \\
\hline Phition china & ww. Dhisidos. com. en \\
\hline Intel Company China & ww. Into1. com. en \\
\hline Hisonse Corporation & wwo bloonso. com \\
\hline Huawol Tochnolorios Co.. Led & mowe huawel. com, en \\
\hline UFIDA Sofiware CO...LTD & www, uraors, com, en \\
\hline Shenzhon Skyworth Eloctronles Co.. Lid & www. skyworth, com, on \\
\hline TCL CORPORATION & wrw. tel. com \\
\hline Lonove & www. lepend, com. en \\
\hline Tolnghua Tongrana CO... LTD & mw. ther. com. on \\
\hline Chunian Groud Cord & www. chusian. com \\
\hline Inspur Group & wow. Inspux. com \\
\hline Konka Group CO. . LTD & www. konka. com \\
\hline Panda Bloctronles Grous Co... Led & www. chlnasanda. com, en \\
\hline Groo Eloctrie ADDilancos. Ine & www. area.com. en \\
\hline Tolnghua Unlspiondour Corporasion Limited & wrow. thunis. com \\
\hline ehanghonk oloctric co.. lid & www, cbankhonk, com, en \\
\hline Avema co.. 1:d & www. avema, com, on \\
\hline Modia in China & nww midoa. com. on \\
\hline BoE Tochnology Groud Co.. Led & www. boe. com, en \\
\hline Grons Wali Tochnoloky Co. Led & www, nxoerwa 11 tech, com \\
\hline Datang Tolocom Technolory Co.. Ltd & mwow. dasenk. com \\
\hline $\begin{array}{l}\text { Oracio company china } \\
\text { conun croup }\end{array}$ & $\begin{array}{l}\text { ww. oracie. com/alobal/en } \\
\text { www. al a oxink. net }\end{array}$ \\
\hline
\end{tabular}

\subsection{Web link data}

In our experiment, we used 17 link analysis indicators to analyze the data, 7 of which is through Google, and 10 of which is through Altavista, as showed in Table 4, 5 (limited space, only display the part business' link data) : 
Table 4: Data from Google search results. This was done from 19:10 to 24:10, on May 1,2007. * represents the abnormal data, which will be discussed in part five

\begin{tabular}{|c|c|c|c|c|c|c|c|}
\hline Oracle coapany & 117000 & 1020000 & 116000 & 993000 & 8.718 & 8.487 & 0.991 \\
\hline IBM China Company Limited & 21 & 36100 & 9 & 36100 & 1719 & 1719 & 4.5 \\
\hline Founder Electronics Co., Lt & 1260 & 24800 & 1300 & 16400 & 19.683 & 13.016 & 1. 032 \\
\hline Haier Co., Ltd & 15100 & 66000 & 12300 & 43900 & 4. 3709 & 2.907 & 0.815 \\
\hline Nokia Mainland Chins & 3890 & 44100 & 3160 & 32700 & 11.337 & 8.406 & 0.812 \\
\hline ZTE Corporation & 11500 & 45100 & 9420 & 18400 & 3.922 & 1.6 & 0.819 \\
\hline Notorola China & 10900 & 45600 & 8490 & 22000 & 4.183 & 2.018 & 0.779 \\
\hline Philips China & 384 & 12100 & 369 & 9170 & 31.51 & 23.88 & 0.961 \\
\hline Intel Coapany China * & 1 & 10400 & 1 & 10900 & 10900 & 10900 & 1 \\
\hline Hisense Corporation & 2270 & 14500 & 2120 & 9810 & 6.388 & 4.322 & 0.934 \\
\hline Juawei Technologies Co., Lte & 148 & 33100 & 9 & 33100 & 223.649 & 223.649 & 0.0608 \\
\hline UFIDA Sof tware CO., LTD & 8850 & 30600 & 7110 & 9350 & 3.458 & 1.056 & 0.803 \\
\hline ien Skyworth Electronics Co. & 127 & 4550 & 127 & 4530 & 35.827 & 35.669 & 1 \\
\hline TCL CORPORATION & 3830 & 13100 & 3190 & 11100 & 3.42 & 2. 898 & 0.833 \\
\hline Lenovo & 95 & 6030 & 82 & 5380 & 63.474 & 56.632 & 0.863 \\
\hline Ts inghua Tongfang C 0. LTD & 313 & 10500 & 306 & 959 & 33.546 & 3. 064 & 0.978 \\
\hline
\end{tabular}

Table 5: Data from Altavistasearch results. This was done from 19:10 to 24:10, on May 1,2007. * represents the abnormal data, which will be discussed in part five

\begin{tabular}{|c|c|c|c|c|c|c|c|c|c|c|}
\hline Eatorpriso Masao & $\mathrm{T}$ & L & S1 & S2 & B1 & B2 & B3 & IIP & VIFo & YIPs \\
\hline Microsoft Corporation & 27900000 & 92000000 & 243000 & 244000 & 1250000 & 1250000 & 3380000 & 3. 287 & 0.07 & 0.009 \\
\hline Intel Company & 8890000 & 31500000 & 26000 & 26000 & 253000 & 259000 & 884000 & 3. 543 & 0.052 & 0.003 \\
\hline Founder China & 8650000 & 20200000 & 133 & 140 & 20200 & 20600 & 22000 & 2. 335 & 0.0024 & 0 \\
\hline IBM & 9210000 & 25200000 & 166000 & 167000 & 190000 & 190000 & 1290000 & 2. 736 & 0.06 & 0.018 \\
\hline Konka Group & 2910 & 82000 & 444 & 445 & 16000 & 16000 & 24800 & 28.179 & 6.506 & 0.153 \\
\hline awei Technologies Co., Lt & 1400 & 63400 & 692 & 824 & 32500 & 32700 & 26300 & 45. 286 & 21.786 & 0.541 \\
\hline Oracle China. & 182000 & 314000 & 0 & 0 & 754 & 757 & 756 & 1. 725 & 0.004 & 0 \\
\hline DELL Company & 5900000 & 33800000 & 6600 & 6630 & 139000 & 140000 & 377000 & 5. 729 & 0.037 & 0.001 \\
\hline Intel Company China & 175000 & 752000 & 32800 & 35400 & 23800 & 23700 & 19200 & 4. 297 & 0.172 & 0.195 \\
\hline ng Telecon Technology Co. & 59400 & 398000 & 29 & 29 & 1820 & 1820 & 3630 & 6.7 & 0.041 & 4. 882 \\
\hline Philips Chias* & 57900 & 128000 & 2 & 2 & 18800 & 18700 & 27500 & 2. 211 & 0.374 & \\
\hline IBM China & 216000 & 612000 & 108000 & 117000 & 21000 & 21000 & 30500 & 2.833 & 0.112 & 0.521 \\
\hline Haier Group & 114,000 & 834000 & 55 & 180 & 36800 & 36800 & 47800 & 7. 316 & 31.947 & 0.004 \\
\hline Hisense Group & 1,640 & 160000 & 119 & 120 & 22500 & 22400 & 33000 & 97.561 & 142. 500 & 0.291 \\
\hline 2TE Corporation & 770 & 32400 & 149 & 149 & 17700 & 17600 & 17400 & 42. 078 & 22.814 & 0.194 \\
\hline
\end{tabular}

\section{Data analysis}

Table 4 and Table 5 shows, use Google search and Altavista search for the enterprise links indicators specific data gap greatly. For example : the value of WIF, WIFe, WIFs of Microsoft website were $26.655,4.286,1.484$ with Google, while with Altavista were $3.287,0.07$. 0.009. Clearly, database capacity and search mechanism of the two tools are different. If only using the original data to evaluate and rank, the conclusion wouldn't be objective. Therefore, we score each of the indicators, and then add in all indicators to gain final scores., and produce a total ranking, as showed in Table 6,7,8 (Due to space limitations, only display the total ranking of the top 20 enterprise-data) : 
Table 6 : rankings of enterprises site searched by Google

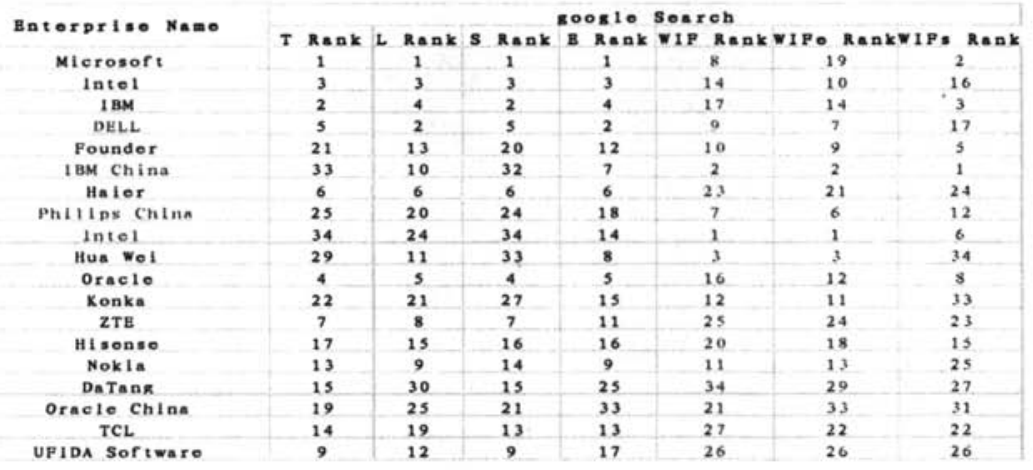

Table 7 : rankings of enterprises site searched by Altavista

\begin{tabular}{|c|c|c|c|c|c|c|c|c|c|c|}
\hline Enterprise $\mathrm{Name}$ & & & & & altav & Wistas & Soureh & & & \\
\hline & T Rank. & $R=n \times 1$ & $\operatorname{Ran} 3$ & $2 R=n B$ & $1 R \operatorname{Rnk}$ & 2 Raniz & IE $3 \mathrm{kank}$ & $K \perp F=n$ & Nee kank & $1 F=k a n k$ \\
\hline Microsor: & 1 & 1 & 1 & 1 & 1 & 1 & 1 & 19 & 27 & 23 \\
\hline Intel & 3 & 3 & 5 & 5 & 2 & 2 & 3 & 18 & 29 & 26 \\
\hline $1 \mathrm{BM}$ & 2 & 2 & 8 & 8 & 4 & 4 & 5 & 12 & 32 & 29 \\
\hline DELL. & 6 & 6 & 6 & 6 & $s$ & 5 & 4 & 23 & 30 & 28 \\
\hline Founder & 4 & 4 & 2 & 2 & 3 & 3 & 2 & 27 & 28 & 21 \\
\hline IBM China & 8 & 8 & 23 & 19 & 9 & 9 & 9 & 9 & 11 & 24 \\
\hline Haler & 12 & 12 & 10 & 10 & 8 & 8 & 7 & 22 & 23 & 22 \\
\hline Philiox China & 15 & 15 & 20 & 22 & 12 & 12 & 10 & 1 & 3 & 13 \\
\hline Intel & 10 & 10 & 3 & 3 & 13 & 13. & 11 & 24 & 26 & 9 \\
\hline Hus wel & 19 & 19 & 12 & 11 & 10 & 10 & 13 & 2 & 13 & 8 \\
\hline Oracle & 5 & 3 & 19 & 21 & 14 & 14 & 16 & 28 & 34 & 34 \\
\hline Konka & 17 & 17 & 9 & 9 & 6 & 6 & 6 & 17 & 15 & 12 \\
\hline ZTE & 20 & 20 & 18 & 20 & 16 & 16 & 18 & 4 & 12 & 16 \\
\hline Hisense & 18 & 18 & 14 & 15 & 17 & 17 & 15 & 5 & 18 & 17 \\
\hline Nokia & 11 & 11 & 24 & 24 & 26 & 26 & 27 & 10 & 31 & 3 \\
\hline Datang & 14 & 14 & 7 & 2 & 3 & 7 & 8 & 20 & 21 & 18 \\
\hline Oracio China & 9 & 9 & 4 & 4 & 11 & 11 & 17 & 13 & 25 & 15 \\
\hline TCL. & 7 & 7 & 22 & 13 & 18 & 18 & 14 & 32 & 24 & 27 \\
\hline UFIDA Soriware & 28 & 28 & 15 & 16 & 21 & 21 & 20 & 31 & 7 & 5 \\
\hline
\end{tabular}

Table 8 : total rankings of enterprises site searched by Google and Altavista

\begin{tabular}{|c|c|c|c|c|}
\hline \multirow[t]{2}{*}{ Enterpelae Name } & \multicolumn{2}{|c|}{ Coosio Soureh } & \multicolumn{2}{|c|}{ Altavlata Soareh } \\
\hline & Totel Score & $R=n k \quad 1$ & rotal seore & $R a n k 2$ \\
\hline Mierosof: & 212 & 1 & 274 & 1 \\
\hline Intel & 193 & 4 & 254 & 2 \\
\hline $1 \mathrm{BM}$ & 199 & 2 & 244 & 4 \\
\hline DELL & 198 & 3 & 231 & 8 \\
\hline Founder & 155 & 7 & 254 & 3 \\
\hline 18M China & 158 & 6 & 221 & 12 \\
\hline Holer & 153 & 8 & 216 & 13 \\
\hline Philips China & 133 & 12 & 227 & 11 \\
\hline Intel & 131 & 13 & 228 & 9 \\
\hline Hun voi & 124 & 15 & 233 & 6 \\
\hline Oracle & 191 & 5 & 160 & 19 \\
\hline Konka & 104 & 23 & 236 & 5 \\
\hline ZTE & 140 & 10 & 190 & 15 \\
\hline Hisonse & 128 & 14 & 196 & 14 \\
\hline Nokin & 151 & 9 & 157 & 21 \\
\hline Datans & 70 & 32 & 227 & 10 \\
\hline Oracle China & 62 & 33 & 232 & 7 \\
\hline TCL & 115 & 18 & 168 & 17 \\
\hline UFIDA Sortware & 120 & 16 & 158 & 20 \\
\hline
\end{tabular}




\section{Experiment results and discussion}

\section{1 discussion on link analysis tools}

In Webometrics study, the Altavista is the preferred search engine for researchers [8].Can we take it with other tools in the integrated use to achieve optimal results? We can answer it with Table 8: In Ranking 1,2 and total ranking order, the first one are both Microsoft and are consistent with the total order; while the second one is slightly different, that is IBM Corporation with Google search results, but with Altavista search results and overall rankings are both Intel Corporation; Hisense Group, in an order, are all ranked 14th in the Sort 1 ,Sort 2 and the total ranking ; TCL Group, Sort 1 Sort 2 and the total ranking is in turn No. 18 , No. 17 and No. 18, a difference of weak. The resulting gains rough conclusions: Google web links can be as analytical tools used in conjunction with the Altavista. Although both the search results with slight deviation, they can achieve balance and comprehensive abatement through synthesizing indicators. This from another angle test our hypothesis : Altavista can make integrated use with other web link tools to achieve optimal results.

\section{2 indicators and enterprises web influence}

In Table 4 and Table 5, the Enterprise website with * sign can be seen, and abnormal data mainly exist in the indicators $\mathrm{S}$ and WIFs of all these indicators, while for indicators $\mathrm{E}$ and WIFe, with either Google or Altavist retrieval, the results are relative normal. Therefore, we can deduce: indicators $\mathrm{E}$ and WIFe is the most effective indicators of many indicators for website link analysis and its influence force evaluation.

As for the underlying factors for fluctuation of value in Table 6 and Table 7, which caused the inconsistencies of two search engines link analysis results, come from such objective reasons as the dynamic network information variability characteristics and the different search mechanisms of the search engine, simultaneously; this also reflects the availability of some enterprises websites being in question. In many literature of evaluating websites, availability is a major indicators which include the appearance ratio of webpages in search engine, the structure level of website resources and the effectiveness of internal link [14]. However, from Table 4, 5, we can see some abnormal data that produced using Google and Altavista search, such as the value is 0 or 1 of $T, S$. For example, the indicators $T$, indicators $S$ and indicators WIFs of Intel(China) website are 1, while for IBM (China) they were respectively 21,9 and 4.5, and Huawei' $S$ value is 9, using Google. With Altavista search, for Oracle Corporation (China), Shenzhen Skyworth Electronics Co., Ltd. and Panda Electronics Group Limited, are all 0 of S1, S2; for Philips (China), S1, S2 are 2; as for Chunlan Group Limited and Changhong Electronic Co. Ltd. , S1, S2 are 1, Great Wall Technology Co.Ltd., $T$ is 1 . These shown: without regard to search engines factors, the appearance ratio of webpages in search engine, the structure level of website resources and the effectiveness of internal link of these enterprise are not optimistic concept.

Finally, based on the assumptions of relatively availability of our retrieval and analysis tools, we can further explore the difference of some website and how such factors influence the correlation between website and its web influence, in terms of Chinese enterprises and 
other country enterprises, information display websites and online trading sites, and different industries type. So we can provide reference information for Chinese enterprises to optimize website construction and upgrade website influence force.

(1) Disparity exists between Sino-foreign enterprises web influence .Results from the Comprehensive rankings can be seen in this paper, selected 34 Chinese and foreign enterprises, several of the top foreign enterprises are websites, such as Microsoft, Intel, IBM, DELL, only the second one is the Founder Group, IBM Corporation (China), Haier Group, Philips (China), Intel (China), Huawei. This shows that, there is still a big gap between Chinese enterprises on the web site construction and promotion network in comparison with foreign countries. The existing causes include our late started Enterprise Informatization, infrastructure lags and other objective reasons. Furthermore, Chinese enterprises' decision-making should build awareness of the importance of websites on. From the enterprise marketing strategy, enterprises website is a integrated network marketing tools. So with an influential corporate website will enable enterprises to operate its entities into unexpected virtuous circle.

(2) Web influence depend on industries type. While the selection of samples have been taken into account the relationship between nature of the trade and its website construction and only selected information technology businesses and consumer electronic products enterprises, we study still found that these two field industries site also exist differences. Overall, the web influence of information technology and software products enterprises website is bigger than that of the consumer electronics business. From Table 6, 7, 8 in the rankings, we can see that the information technology or information products corporations like Microsoft, Intel, IBM, DELL, Founder, Huawei website ranks forward, but consumer electronics companies such as Haier, Konka, etc. were ranked then. So, the enterprise website building and the diffusion of different industries can take different strategies according to the characteristics of enterprises. A reasonable position of sites function is the premise to achieve perfect networks influence force for the enterprise.

(3) Web influence is relational with its function type. According to the scale and function, websites can be divided into three broad categories: information display only, online direct marketing websites, and e-commerce website[11].Information display-only website is an information carrier, the main function of which is to publish and display information (e.g. Konka $\mathrm{Co}$.). If website add online orders and payment functions, it has the online marketing conditions (e.g. DELL Co.), who is on the initiative of the "linear ordering patterns." If website includes the entire business process integration of information processing systems, it is an e-commerce website (e.g. Haier Co.).

In this paper, the enterprise website link analysis and web influence evaluation showed that DELL website is better than Haier Group, and Haier Group is better than Konka Group. We presumably think that web influence and enterprises' functional types are correlated, that is, the online direct marketing enterprise website influence is better than integrated ecommerce websites and an integrated e-commerce website is better than the display of information for enterprises.

But, as for the accuracy of the results, Ronald Rousseau found that the flaw of AltaVista's arithmetic lead significant fluctuations of the search result [9]. At the same time, we may have missed some related businesses in selecting samples. What we have done is just selecting parts of business websites as representative to analyze so as to describe the problem existing. Therefore, these shortcomings and deficiencies may lead to the research errors. It suggests that it is important to reasonably understand the data results and analysis conclusions when referring to this evaluation ranking, which is also the direction we should improve. 


\section{Acknowledgement}

This article is supported by National Natural Science Foundation of China (70673071).

\section{References}

1. Alexasir,com (January 10, 2007);http://www.alexasir.com/tech.html.

2. Cec-ceda, org (January 7,2007 ); http://www.cec-ceda.org.cn/yxqywz/pxbz.htm

3. Forrester (January 12, 2007); http://www.forrester.com.

4. A.B. Huang, D.M. Zhao, "A research on the evaluation indicator system for $B 2 C$ website", Commercial Research, 2006(1): 192-194.

5. Ingwersen. "The calculation of WEB attractiveness factor", Journal of Documentation, 1998, 54, 236-243 www.//bacterio.cict.fr/backlinks.html.

6. Y.H. Li, S.J. Tang, "An evaluation on electric business website", Library Theory and Practice, 2006(1): 64-65.

7. Marcomconsulting (January 6, 2006);http://www.marcomconsulting.net

8. M. Thelwell, "A Comparation of Source of Links for Academic Web Attractiveness Factor Calculations", Journal of Documentation, 2002, 58(1), 60-72.

9. R. Rousseau, "Daily time series of common single worsearches in AltaVista and Northern Light", [2007-3-2]http://cybermetrics.cindoc.csic.es/pruebas/v2il p2.htm.

10. T. Yang, "The Webometrics Study of Twenty China Mainland Universities", Library and Information Service, 2003(9): 61-66.

11. Z.P. Wang, web marketing, Wuhan: Central China normal university press, $2003.9:$ P53-58.

12. J.K. Xu, "Studying by Comparison the Four Searching Engines in Common Use in the Research of Network Information Measurement", New Technology of Library and Information Service, 2004(11): 46-48.

13. M.Z. Yang, Y.L. Zhuang, "A summary on the theory and practice for e-business website evaluation", Market Modernization, 2006(2): 140-141.

14. Y. Zhang, Q.H. Zhu, "Application of Fuzzy Analytic Hierarchy Process for Enterprises Websites Evaluation", New Technology of Library and Information Service, 2006(6):6871 . 